Jurnal Sakinah Dharmasraya, Vol. 2, No. 2, 2017

\title{
PEMBUKTIAN PENDEKATAN CERTANTY FACTOR PADA EXPERT SISTEM UNTUK MENENTUKAN JENIS GANGGUAN PERKEMBANGAN PADA ANAK
}

\author{
Adi Fitra Andikos \\ Jurusan Manajemen Pendidikan Islam- STITNU SAKINAH Dharmasraya \\ Jln. Lintas Sumatera No. 99 Koto Baru, Dharmasraya 27681 \\ Email: Andicos_afa@yahoo.co.id
}

\begin{abstract}
Abstrak
Expert Sistem merupakan salah satu aplikasi pengembangan dari Artificial Intelligence. Kemampuan Expert Sistem untuk menyelesaikan berbagai tugas yang biasa dikerjakan oleh para ahli menjadi daya tarik tersendiri bagi sistem tersebut. Expert Sistem memiliki beberapa pendekatan seperti: Fc (Runut Maju), Bc ( Runut Mundur), FcBc (Runut Maju dan Mundur). Expert Sistem telah digunakan sebagai alat bantu dalam berbagai bidang kehidupan. Salah satu contoh aplikasi yang dapat dibuat yaitu menentukan jenis gangguan perkembangan pada anak. Dalam penelitian ini akan dilakukan pembuktian Expert Sistem menentukan jenis gangguan perkembangan pada anak dengan pendekatan Certanty Factor pada metode inference maju. Dengan diterapkan Expert Sistem dalam menentukan jenis gangguan perkembangan pada anak, diharapkan dalam proses analisis hasil menjadi lebih cepat dan kesalahan manusia dapat dikurangi. Hasil analisis Expert Sistem pada menentukan jenis gangguan perkembangan pada anak dapat diketahui secara langsung untuk membantu dalam mengetahui menentukan jenis gangguan perkembangan pada anak apa yang diderita dan apa solusinya.
\end{abstract}

Keywords: sxpert sistem, inference maju, certanty factor, Gangguan.

\section{Pendahuluan}

Perkembangan komputer dewasa ini telah mengalami banyak perubahan yang sangat pesat, seiring dengan kebutuhan manusia yang semakin banyak dan kompleks. Hal ini mendorong para ahli untuk semakin mengembangkan komputer agar dapat membantu kerja manusia atau bahkan melebihi kemampuan kerja manusia. Kecerdasan buatan atau Artificial Intelligence merupakan bagian dari ilmu komputer yang membuat agar mesin (komputer) dapat melakukan pekerjaan seperti dan sebaik yang dilakukan oleh manusia. Sistem cerdas (Intelligent System) adalah sistem yang dibangun dengan menggunakan teknik-teknik Artificial Intelligence. Salah satu yang dipelajari pada kecerdasan buatan adalah teori kepastian dengan menggunakan teori Certainty Factor $(C F)$ [8].

Sistem Pakar (Expert System) adalah program berbasis pengetahuan yang menyediakan solusisolusi dengan kualitas pakar untuk problema-problema dalam suatu domain yang spesifik. Sistem pakar merupakan program komputer yang meniru proses pemikiran dan pengetahuan pakar dalam menyelesaikan suatu masalah tertentu. Implementasi sistem pakar banyak digunakan dalam bidang psikologi karena sistem pakar dipandang sebagai cara penyimpanan pengetahuan pakar pada bidang tertentu dalam program komputer sehingga keputusan dapat diberikan dalam melakukan penalaran secara cerdas. Irisan antara psikologi dan sistem pakar melahirkan sebuah area yang dikenal dengan nama Cognition \& Psycolinguistics. Umumnya pengetahuannya diambil dari seorang manusia yang pakar dalam domain tersebut dan sistem pakar itu berusaha meniru metodelogi dan kinerjanya (Performance) [10].

Salah satu implementasi yang diterapkan sistem pakar dalam bidang psikologi, yaitu untuk sistem pakar menentukan jenis gangguan perkembangan pada anak. Anak-anak merupakan fase yang paling rentan dan sangat perlu diperhatikan satu demi satu tahapan perkembangannya. Contoh satu bentuk gangguan perkembangan adalah Conduct Disorder. Conduct Disorder adalah satu kelainan perilaku seorang anak sulit membedakan benar salah atau baik dan buruk, sehingga anak merasa tidak bersalah walaupun sudah berbuat kesalahan. Dampaknya akan sangat buruk bagi perkembangan sosial anak tersebut. Oleh karena itu dibangun suatu sistem pakar yang dapat membantu para pakar/ psikolog anak untuk menentukan jenis gangguan perkembangan pada anak dengan menggunakan metode Certainty Factor (CF) pada expert sistem (Sistem Pakar) dengan inference maju.

\section{Kajian Pustaka}

\subsection{Kecerdasan Buatan}

Kecerdasan buatan dapat didefinisikan sebagai mekanisme pengetahuan yang ditekankan pada kecerdasan pembentukan dan penilaian pada alat yang menjadikan mekanisme itu, serta membuat komputer berpikir secara cerdas. Kecerdasan buatan juga dapat didefinisikan sebagai salah satu bagian ilmu komputer yang membuat agar mesin (komputer) dapat melakukan pekerjaan seperti dan sebaik yang dilakukan manusia 
Jurnal Sakinah Dharmasraya, Vol. 2, No. 2, 2017

Teknologi kecerdasan buatan dipelajari dalam bidang-bidang, seperti: robotika, penglihatan komputer (Computer Vision), jaringan saraf tiruan (Artifical Neural System), pengolahan bahasa alami (Natural Language Processing), pengenalan suara (Speech Recognition), dan sistem pakar (Expert System).

\subsection{Sistem Pakar}

Sistem pakar (Expert System) secara umum adalah sistem yang berusaha mengadopsi pengetahuan manusia ke komputer, agar komputer dapat menyelesaikan masalah seperti yang biasa dilakukan oleh para ahli. Atau dengan kata lain sistem pakar adalah sistem yang didesain dan diimplementasikan dengan bantuan bahasa pemrograman tertentu untuk dapat menyelesaikan masalah seperti yang dilakukan oleh para ahli. Sistem pakar merupakan cabang dari Artificial Intelligence (AI) yang cukup tua karena sistem ini telah mulai dikembangkan pada pertengahan tahun 1960. Sistem pakar yang muncul pertama kali adalah General-purpose problem solver (GPS) yang dikembangkan oleh Newl dan Simon. Sampai saat ini sudah banyak sistem pakar yang dibuat, seperti MYCIN, DENDRAL, XCON \& XSEL, SOPHIE, Prospector, FOLIO, DELTA, dan sebagainya [10].

\subsection{Representasi Pengetahuan}

Representasi pengetahuan adalah suatu teknik untuk merepresntasikan basis pengetahuan yang diperoleh kedalam suatu skema/diagram tertentu sehingga dapat diketahui relasi/keterhubungan antara suatu data dengan data lainnya [6].

Pengetahuan dapat direpresentasikan dalam berbagai model, beberapa model representasi pengetahuan seperti:

a) Logika

Logika merupakan suatu pengkajian ilmiah tentang serangkaian penalaran, sistem kaidah, dan prosedur yang membantu proses penalaran. Bentuk logika komputasional ada 2 macam, yaitu:

1. Logika Proposional

Logika proposional merupakan suatu pernyataan yang menyatakan benar (TRUE) atau salah (FALSE) yang dihubungkan dengan menggunakan operator logika seperti konjungsi (AND), disjungsi (OR), negasi (NOT), implikasi/kondisional (If...Then), equivalensi/bikondisional (If and only If).

2. Logika Predikat

Logika predikat merupakan suatu logika yang seluruhnya menggunakan konsep dan kaidah proporsional yang sama, disebut juga kalkulus predikat, yang memberi tambahan kemampuan untuk merepresentasikan pengetahuan dengan sangat cermat dan rinci.

b) Jaringan Semantik

Jaringan semantik merupakan representasi yang menggambarkan grafis dari pengetahuan yang memperlihatkan hubungan hirarkis dari objek-objek yang terdiri atas simpul (node) dan penghubung (link). Berikut adalah contoh gambar model representasi pengetahuan jaringan semantik:

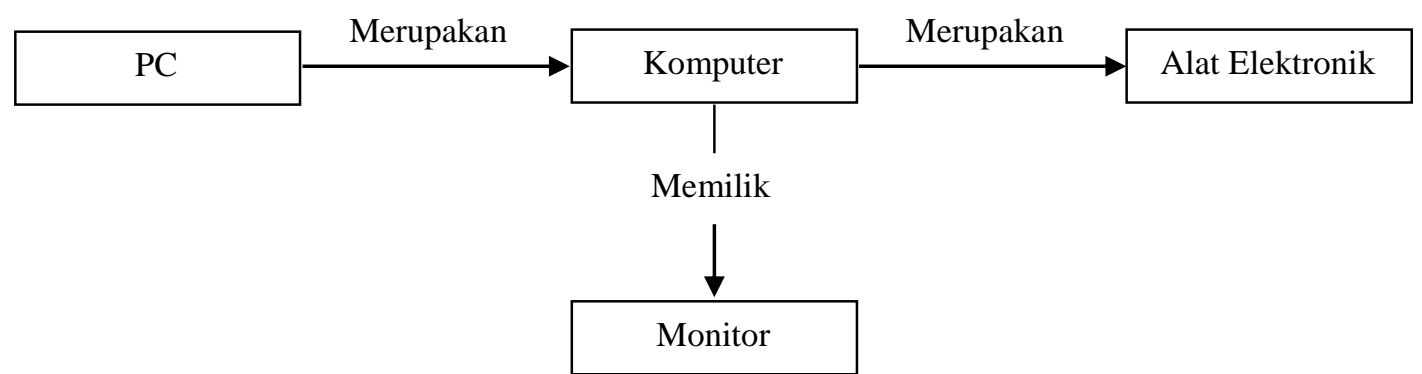

Gambar 2.1 Representasi Jaringan Semantik

c) Object-Atributte-Value (OAV)

Object dapat berupa bentuk fisik atau konsep. Attribute adalah karakteristik atau sifat dari object tersebut. Value (nilai) - besaran spesifik dari attribute tersebut yang berupa numerik, string atau Boolean.

Berikut adalah contoh tabel model representasi pengetahuan Object-Atributte-Value (OAV):

Tabel 2.1 Representasi OAV

\begin{tabular}{|c|c|c|}
\hline Object & Attribute & Value \\
\hline Mangga & Warna & Hijau, Orange \\
\hline
\end{tabular}


Jurnal Sakinah Dharmasraya, Vol. 2, No. 2, 2017

d) Bingkai ( Frame)

\begin{tabular}{|c|c|c|}
\hline Mangga & Biji & Tunggal \\
\hline Mangga & Rasa & Asam, Manis \\
\hline Mangga & Bentuk & Oval \\
\hline Pisang & Warna & Hijau, Kuning \\
\hline Pisang & Bentuk & Lonjong \\
\hline
\end{tabular}

Bingkai berupa ruang ( Slots ) yang berisi atribut untuk mendeskripsikan pengetahuan yang berup kejadian, lokasi situasi ataupun elemen - elemen lain.

Berikut adalah contoh tabel Model Representasi pengetahuan bingkai (Frame)

Tabel 2.2 Representasi Bingkai Pada Bingkai Penyakit

\begin{tabular}{|l|l|}
\hline \multicolumn{1}{|c|}{ Ruang ( Slots ) } & \multicolumn{1}{c|}{ Isi ( Fillers ) } \\
\hline Nama & Flu \\
\hline Gejala & a. Bersin \\
& b. Pusing \\
\hline Obat & c. Demam \\
& a. Ultraflu \\
& b. Mixagrib \\
\hline
\end{tabular}

e) Kaidah Produksi

Kaidah menyediakan cara formal untuk merepresentasikan rekomendasi, arahan atau strategi dalam bentuk jika - maka ( If - Then ) yang menghubungkan anteseden dengan konsekuensi.

Berikut adalah contoh model representasi pengetahuan kaidah poduksi:

JIKA bersin

DAN pusing

DAN demam

MAKA terserang penyakit flu

Tujuan dari sistem pakar adalah mentranfer kepakaran yang dimiliki seorang pakar kedalam komputer dan kemudian kepada orang lain ( non expert ). Dimana aktivitas pemindahahan kepakaran sebagai berikut :
a. Knowledge Acquisition ( dari pakar atau sumber lain )
b. Knowledge Representation ( ke dalam komputer )
c. Knowledge Inferencing
d. Knowledge Transfering

\subsection{Metode Inferensi}

Metode inferensi merupakan suatu cara penarikan kesimpulan yang dilakukan oleh mesin inferensi untuk menyelesaikan masalah. Ada dua metode inferensi yang umum dalam sistem pakar, yaitu:

\section{Forward Chaining (Runut Maju)}

Forward chaining adalah suatu strategi pengambilan keputusan yang dimulai dari bagian premis (fakta) menuju konklusi (kesimpulan akhir) [10]. Metode inferensi ini yang akan digunakan dalam sistem pakar yang akan dibangun dengan contoh penalaran sebagai berikut:

IF Sulit bernafas

AND Pilek

AND Batuk kering

AND Tarikan nafas berbunyi kasar dan penghembusan nafas berbunyi mengi

THEN Laringitis

Secara sederhana dapat dijelaskan bahwa untuk kaidah diatas, agar sistem mencapai konklusi, harus diinput terlebih dahulu fakta sulit bernafas, pilek, tarikan nafas berbunyi kasar dan penghembusan nafas berbunyi mengi. Baru sistem dapat mengeluarkan konklusi bahwa penyakit yang diderita adalah laringitis.

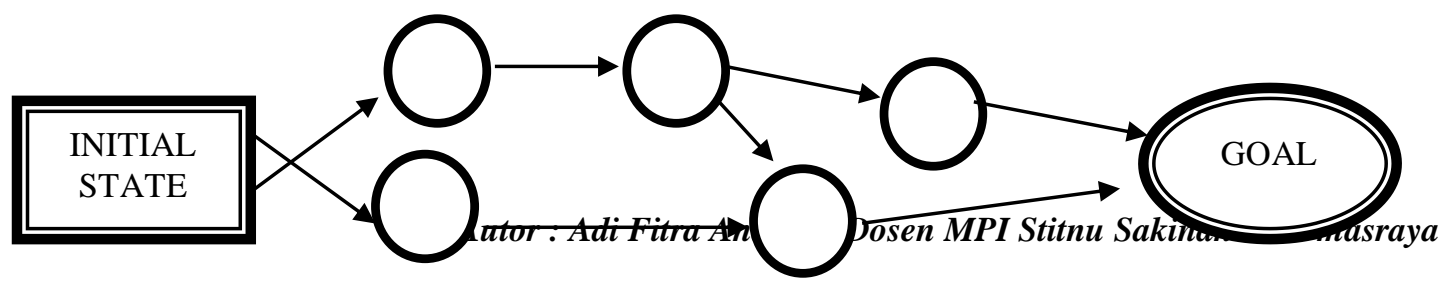




\section{Gambar 2.2 Siklus Forward Chaining}

1. Forward chaining secara bertahap membentuk gambaran baru akan dunia bersamaan dengan penerimaan data, forward chaining tidak diarahkan untuk menyelesaikan suatu permasalahan tertentu, karenanya metoda ini disebut juga data- driven atau data- dir ected procedure.

2. Forward chaining dapat menghasilkan banyak kesimpulan yang pada akhirnya tidak digunakan (sia-sia)

2. Backward Chaining (Runut Balik)

Backward chaining adalah suatu strategi pengambilan keputusan dimulai dari pencarian solusi dari kesimpulan kemudian menulusuri fakta-fakta yang ada hingga menemukan solusi yang sesuai dengan fakta-fakta yang diberikan pengguna [10]. Contoh penalaran backward chaining adalah:

Lampu 1 rusak,

IF Lampu 1 dinyalakan

AND Lampu 1 tidak menyala

AND Lampu 1 dihubungkan dengan sekering

AND sekering masih utuh

Secara sederhana dapat dijelaskan bahwa untuk kaidah diatas, sistem terlebih dahulu menduga bahwa lampu 1 rusak. Kebenaran praduga ini dibuktikan dengan kebenaran fakta lampu 1 tidak menyala, lampu 1 dihubungkan dengan sekering dan sekering masih utuh. Kemudian sistem mengeluarkan kesimpulan bahwa lampu 1 rusak. Namun apabila ada fakta tidak terpenuhi berarti praduga sistem salah, selanjutnya sistem akan mengecek konklusi berikutnya.

\section{Metodologi Penelitian}

Dalam pengumpulan data untuk menyusun penulisan ilmiah ini penulis melakukan dengan cara studi pustaka dengan mengumpulkan data yang didapat dari membaca buku, Reviw journal, internet serta literature yang dapat menunjang penulisan tersebut.

Penelitian ini dilakukan dengan beberapa tahapan, yaitu:

a) Pembelajaran Literatur

Metode ini dilaksanakan dengan melakukan studi kepustakaan melalui membaca buku-buku maupun artikel-artikel yang dapat mendukung penulisan Tesis ini.

b) Analisis

Pada tahap ini dilakukan pengumpulan fakta-fakta yang mendukung perancangan sistem dengan mengadakan konsultasi dengan seorang pakar (dokter spesialis anak) dan membandingkan hasil penelitian dengan yang ada pada buku penuntun.

c) Perancangan

Pada tahap ini akan dilakukan perancangan sistem pakar untuk diagnosa penyakit anak.

d) Pengkodean

Pada tahap ini rancangan yang akan dibuat dan dimplementasikan ke dalam bentuk kode program Visual Basic.

e) Pengujian

Setelah proses pengkodean selesai maka akan dilakukan proses pengujian terhadap program yang dihasilkan untuk mengetahui apakah program sudah berjalan dengan benar dan sesuai dengan perancangan yang dilakukan.

f) Penyusunan laporan dan kesimpulan akhir

Membuat laporan hasil analisa dan perancangan ke dalam format penulisan tugas akhir dengan disertai kesimpulan akhir.

\section{Hasil dan Pembahasan}

Analisa kebutuhan merupakan langkah awal untuk menentukan pembuatan sistem seperti apa yang akan dihasilkan, ketika melaksanakan sebuah proyek pembuatan perangkat lunak. Perangkat lunak yang baik dan sesuai dengan kebutuhan pengguna sangat bergantung kepada keberhasilan dalam melakukan analisa kebutuhan. Tidak peduli bagaimana hebatnya seseorang dalam menulis kode perangkat lunak, atau 
membuat antar muka yang menawan, jika terjadi kesalahan dalam analisa kebutuhan maka perangkat lunak yang dibuat menjadi tak berguna.

Pada sistem pakar gangguan perkembangan anak ini, diawali dengan pembuatan sebuah basis pengetahuan. Pengetahuan yang berasal dari pakar tersebut direpresentasikan kedalam bentuk-bentuk satuan pengetahuan sesuai dengan metode representasi pengetahuan yang digunakan, yaitu metode pengetahuan metode frame. Metode pengetahuan yang menggambarkan objeknya dengan lebih terperinci. Rincian dari objek tersebut dibuat dalam bentuk slot yang menggambarkan berbagai atribut dan karakteristik objek.

Proses inferensi yang digunakan dalam arsitektur berbasis frame ini adalah pelacakan maju (Forward Chaining) dan dikombinasikan dengan metode certainty factor (CF). Proses penalaran dimulai dari sekumpulan data yang menuju pada suatu kesimpulan. Dalam penalaran ini aturan (rule) akan diuji melalui penalarannya dari sekumpulan data yang mendukung hipotesa tersebut menuju kesimpulan algoritma. Penalaran maju ( Forward chaining) dimulai dengan mencari informasi mengenai gejala-gejala yang dialami oleh user atau pasien yaitu dengan memberikan pertanyaan yang mempunyai korelasi dengan gejala kepada user, berdasarkan jawaban atas pertanyaan dan nilai kepastian (certainty factor). sistem pakar akan membaca aturan atau (kaidah/fakta) untuk mencari aturan yang cocok, tahap berikutnya sistem pakar akan membaca aturan dan mencocokkannya kembali. Dari proses tersebut akan didapatkan kesimpulan.

\subsection{Analisis Data}

Analisis data adalah proses mendefiniskan semua kebutuhan data agar sistem dapat berjalan dengan baik. Pada sistem pakar ini mengunakan konsep relational database yang berisi kumpulan tabel dalam satu file yang saling berinteraksi satu dengan yang lainnya, dimana setiap tabel mempunyai nama dan struktur yang unik. Dalam setiap tabel, masing-masing record data diorganisasikan dalam struktur yang sama dan memiliki fields kunci yang akan menjadi penghubung antar tabel yang ada dan berkaitan satu dengan yang lainnya.

Beikut ini data yang dibutuhkan pada sistem pakar ini sehingga sistem dapat berkerja dengan baik. data user (pasien), rule, tmp_gejala, jns_gangguan, serta diagnosa. Dan berikut ini adalah struktur tabel yang digunakan.

\section{a. Tabulasi data untuk Pasien}

Tabulasi data tabel dapat juga dinamakan sebagai tabel temporari atau tabel sementara untuk data pasien. Tujuan dibuatnya tabel ini adalah untuk menyimpan data pasien dari form pendaftaran. Berikut struktur tabel pasien.

\begin{tabular}{|l|l|l|l|l|}
\multicolumn{5}{|c|}{ Tabel 4.1 Tabulasi data untuk pasien } \\
\hline 1 & Id_pasien & Int & 4 & PK(Primary Key) \\
2 & Nama & Varchar & 30 & Nama Pasien \\
3 & Kelamin & ENUM & 'P','W' & Jenis Kelamin \\
4 & Umur & Varchar & 2 & Umur ( tahun ) \\
5 & Alamat & Varchar & 2 & Umur ( bulan ) \\
\hline
\end{tabular}

\section{b. Tabulasi data untuk Gejala}

Tabel gejala digunakan untuk menyimpan daftar gejala yang mungkin terjadi pada anak, berikut ini adalah struktur tabel gejala :

Tabel 4.2. Tabulasi data untuk gejala

\begin{tabular}{|l|l|l|l|l|}
\hline 1 & Kd_gejala & Char & 4 & $\begin{array}{l}\text { PK(Primary Key) } \\
\text { Pertanyaan yang } \\
\text { didasarkan pada gejala } \\
\text { yang terdapat pada } \\
\text { pasien }\end{array}$ \\
\hline
\end{tabular}

a. Tabulasi data untuk Rule/ Relasi

Tbl_Relasi berfungsi untuk menghubungkan antara tabel penyakit dengan tabel gejala, sehingga akan dihasilkan suatu daftar gejala yang terjadi pada jenis gangguan.Berikut ini adalah struktur tabel Relasi

Tabel 4.3 Tabulasi data untuk Rule / Relasi 
Jurnal Sakinah Dharmasraya, Vol. 2, No. 2, 2017

\begin{tabular}{|l|l|l|l|l|}
\hline 1 & Id_gangguan & Char & 4 & Kode Penyakit \\
2 & id_gejala & Char & 4 & Kode Gejala \\
\hline
\end{tabular}

a. Tabulasi data untuk Jns_Gangguan

Tabel Jns_gangguan digunakan untuk menyimpan informasi mengenai jenis-jenis gangguan perkembangan serta solusi atau terapi untuk jenis gangguan tersebut.

Tabel 4.4 Tabulasi data untuk Jns_Gangguan

\begin{tabular}{|l|l|l|l|l|}
\hline 1 & Id_gangguan & Char & 4 & PK(Primary Key) \\
2 & Nm_gangguan & Varchar & 60 & $\begin{array}{l}\text { Nm_gangguan } \\
\text { Nilai kepastian yang berasal } \\
\text { dari pakar } \\
\text { CF_gangguan }\end{array}$ \\
4 & Solusi & Text & 4 & $\begin{array}{l}\text { Penjelasan mengenai } \\
\text { gangguan perkembangan }\end{array}$ \\
\hline
\end{tabular}

\subsection{Analisis Proses}

Pada sistem pakar gangguan perkembangan anak ini analisis proses dilakukan untuk mendefinisikan semua kebutuhan proses pada sistem pakar, berikut ini gambaran proses pada sistem pakar gangguan perkembangan pada anak

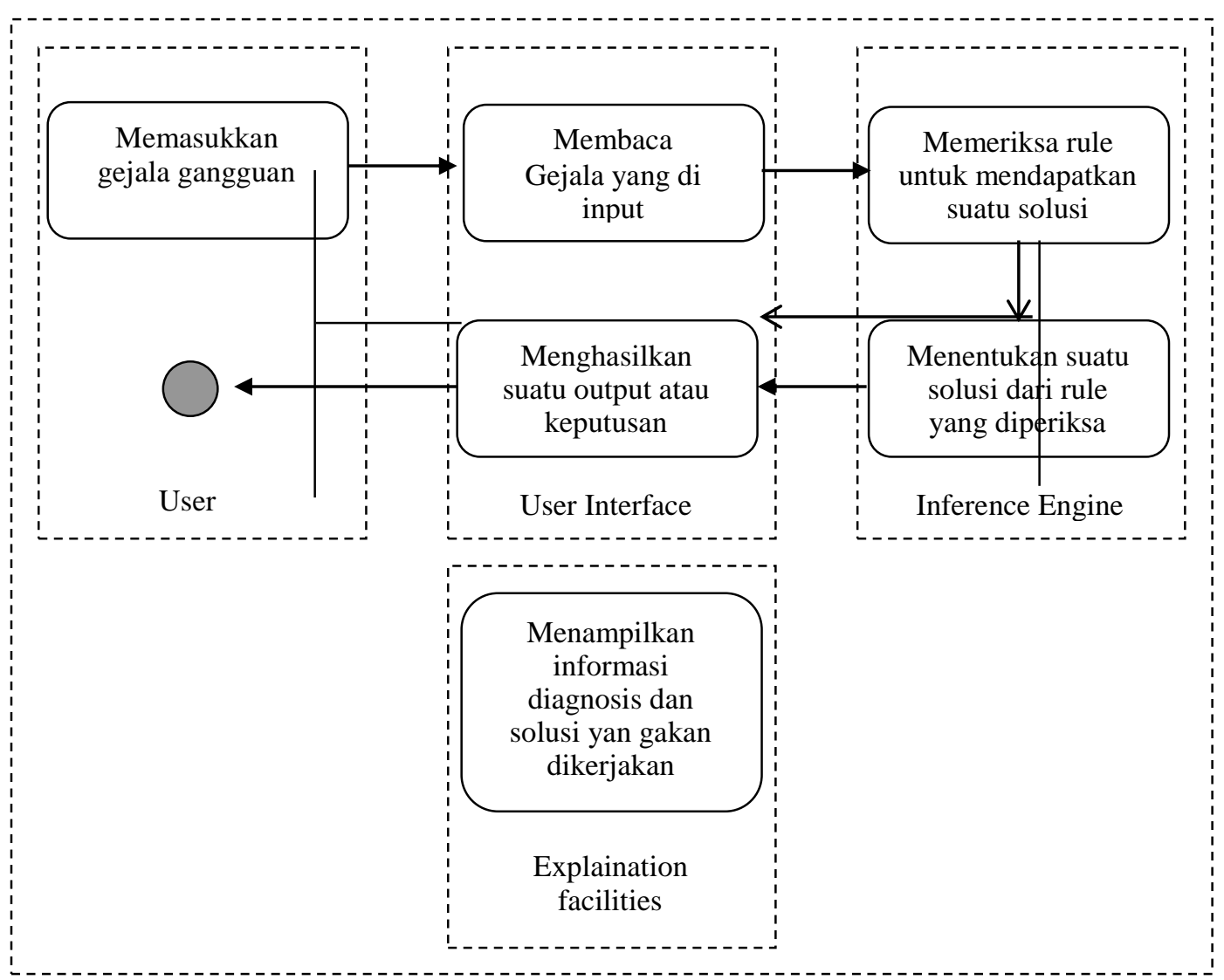

Gambar 4.1. Diagram Aktifitas Sistem

Pada sistem pakar ini, User memasukkan data user, gejala kemudian user interface akan membaca data user dan gejala yang diinputkan oleh user, oleh inference engine gejala yang di inputkan oleh user diperiksa rule-nya, dan menentukan suatu solusi dari rule yang yang diperiksa, berikutnya inference engine akan memberikan solusi yang terbaik, hasil dari diagnosa akan diberikan ke user. Untuk mendapatkan gambaran yang lebih jelas, berikut ini adalah disain arsitekstur sistem pakar gangguan perkembangan pada anak.

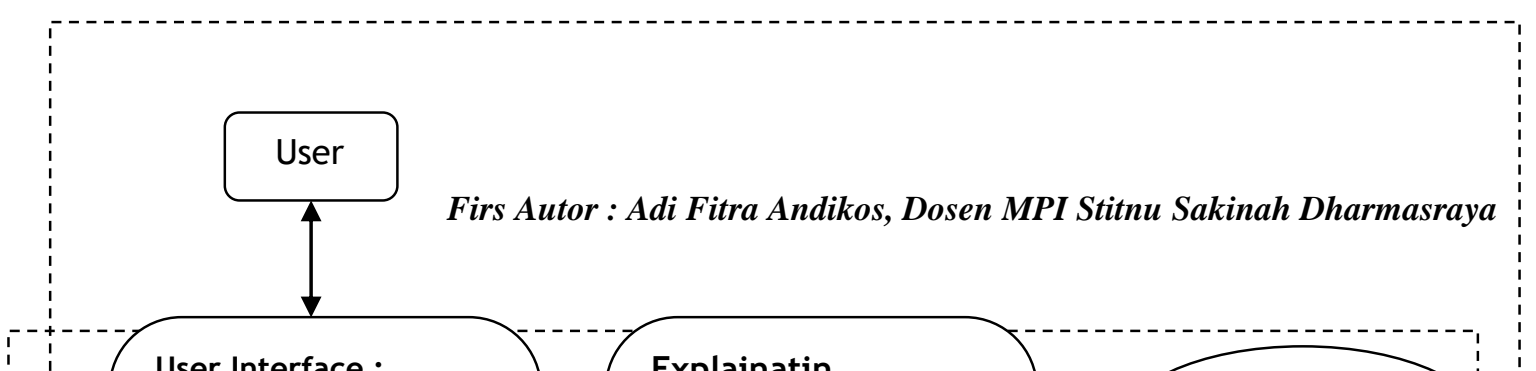




\section{4..2 Arsitektur Sistem Pakar Gangguan Perkembangan Pada Anak}

Komponen-komponen yang ada pada Gambar 4.2 Arsitektur Sistem Pakar adalah sebagai berikut :

a. User (Pemakai), yaitu orang atau pasien yang mengunakan sistem pakar ini, pada tahap ini user menginputkan data diri User atau pasien, kemudian dilanjutkan dengan menginputkan daftar pertanyaan berupa gejala-gejala yang dialami oleh user.

b. User Interface ( antar muka pemakai ), merupakan prosedur untuk membaca fakta-fakta berupa gejala yang dialami oleh user, selain itu user interface ini juga digunakan untuk menampilkan hasil diagnosa berupa jenis ganggua, deskripsi, serta penanggulangannya.

c. Explaining Facilities (Fasilitas Penjelasan), berisi bantuan pengunaan sistem pakar

d. Inference Engine (Mesin Inferensi), berisi prosedur untuk mencocokkan antara fakta dengan aturan.

e. Working Memori (Working Memori), berisi fakta-fakta yang diberikan oleh user berupa jawaban dari pertanyaan.

\subsection{Proses Perancangan Knowledge Base dan Aturan}

Pengetahuan yang digunakan dalam sistem akan direpresentasikan dalam format tertentu yang kemudian akan dihimpun dalam suatu basis pengetahuan. Pada penalaran berbasis aturan, pengetahuan direpresentasikan dengan mengunakan aturan berbentuk If - Then. Bentuk ini digunakan apabila kita memiliki sejumlah pengetahuan pakar pada suatu permasalahan tertentu dan sistem pakar dapat menyelesaikan masalah tersebut secara beruturan, disamping itu bentuk ini juga digunakan apabila dibutuhkan penjelasan jejak ( langkah-langkah ) pencapaian solusi. 
Kaidah If - Then ini akan menghubungkan antecedent dengan concequen yang diakibatkannya. Himpunan aturan / rule mendeskripsikan solusi sesuai dengan pola kaidah yang dibuat. Rule terdiri dari If Park ( anteceden ) dan then park(concequen). If park terdiri dari objek dan nilai yang dihubungkan oleh operator, then park juga terdiri dari objeck dan nilai yang dihubungkan oleh operator.

Dalam penelitian ini, knowledge base berisi nama jenis gangguan perkembangan dan gejalagejalanya. Jenis gangguan perkembangan diasumsikan sebagai objek, dan gejala-gejalnya diasumsikan sebagai daftar atribut. Knowledge tersebut direpresentasikan secara obyek, atribut, value (Object-AttributeValue) (Riley dan Giarratano, 2002) disertai dengan tingkat kepercayaan.

Untuk mempresentasikan pengetahuan dalam menyelesaikan permasalahan ada tidaknya gangguan perkembangan pada anak, terlebih dahulu user atau pasien melakukan registrasi, kemudan sistem pakar akan menampilkan pertanyaan gejala gangguan perkembangan, jawaban yang diberikan oleh user akan disimpan sebagai fakta di database.

Beberapa fakta yang terdapat pada sistem pakar ini adalah fakta data user, fakta jenis gejala, kedua fakta tersebut diatas didapatkan dari registrasi user dan jawaban pertanyaan dari user. Berikut ini adalah fakta yang terdapat pada sistem pakar ini

1. Fakta data user, berisikan data-data user yang berasal dari hasil registrasi user, mengingat untuk dapat menjalankan modul diagnosa, user harus melakukan registrasi terlebih dahulu.

2. Fakta Gejala, Fakta gejala didapat dari jawaban gejala yang di derita oleh user / pasien.

3. Pakar, berisi fakta-fakta pakar sebagai sumber pengetahuan. Sumber pengetahuan ini sendiri bisa berupa jenis gangguan, gejala, serta solusi atau terapi dari jenis gangguan tersebut

4. Terapi atau solusi, fakta mengenai terapi yang diberikan berdasarkan dari jenis gangguan

\subsection{Proses Kerja Mesin Inferensi}

Seperti yang sudah dijelaskan sebelumnya bahwa pada sistem pakar ini, mengimplementasikan mesin inferensi dengan menggabungkan antara metode forward chaining dengan certainty factor (CF) dalam mencari sebuah penyelesaian.

Forward chaining adalah suatu pendekatan ke arah data-driven karena inferensi dimulai dengan informasi yang tersedia dan baru konklusi diperoleh, Penyesuaian seluruh fakta atau pertanyaan pada inferensi forward chaining merupakan metode inferensi yang melakukan penalaran dari suatu masalah kepada solusinya dimulai dari sebelah kiri dulu (IF dulu). Dan Jika klausa premis sesuai dengan situasi (bernilai TRUE), maka proses akan menyatakan konklusi

Berikut ini adalah proses kerja dari mesin inferensi ( inference engine ) :

1. Mencari rule untuk menentukan gejala, diagnosa, solusi, dan knowledge serta aturan.

2. Penelusuran tentang gejala gangguan dilakukan didasarkan pada pertanyaan yang diberikan kepada user,

3. Berdasarkan pada jawaban dan nilai ketidakpastian (CF) dari user kemudian dimasukkan kedalam tabel kerja sementara.

4. Mesin Inferensi (Inference Engine) akan mengsortir rule berdasarkan dari jawaban user untuk disesuaikan dengan diagnosa dan solusi yang diberikan.

Proses implementasi mesin inferensi yang menggunakan forward chaining dan certainty factor (CF) dapat digambarkan pada tabel berikut ini :

Tabel 4.5. Database Yang Mengandung Fakta Gejala

\begin{tabular}{|l|l|l|}
\hline Kode & Fakta & Jenis Gangguan \\
\hline G001 & Tingkat IQ kurang dari 19 & $\begin{array}{l}\text { Reterdasi Mental Sangat } \\
\text { Berat }\end{array}$ \\
G002 & Sangat terbelakang & \\
G003 & Koordinasi otot sedikit sekali & \\
G004 & Kemungkinan tidak dapat berbicara atau berjalan & \\
G006 & Sulit focus & Reterdasi Mental Berat \\
G007 & Dingkat IQ 20 s.d 35 & \\
G008 & Tidak mengucapkan beberapa kata & \\
G009 & sekali & \\
G010 & Tingkat IQ antara 36 s.d 31 & Reterdasi Mental Moderat \\
G011 & Bisa berbicara atau belajar berkomunikasi & \\
G012 & Kesadaran sosial kurang & \\
G013 & Koordinasi otot cukup & Reterdasi Mental Ringan \\
G014 & Tingkat IQ antara 52 s.d 68 & \\
G015 & Bisa membangun kemampuan sosial dan komunikasi & \\
G016 & Koordinasi otot sedikit terganggu & \\
\hline
\end{tabular}




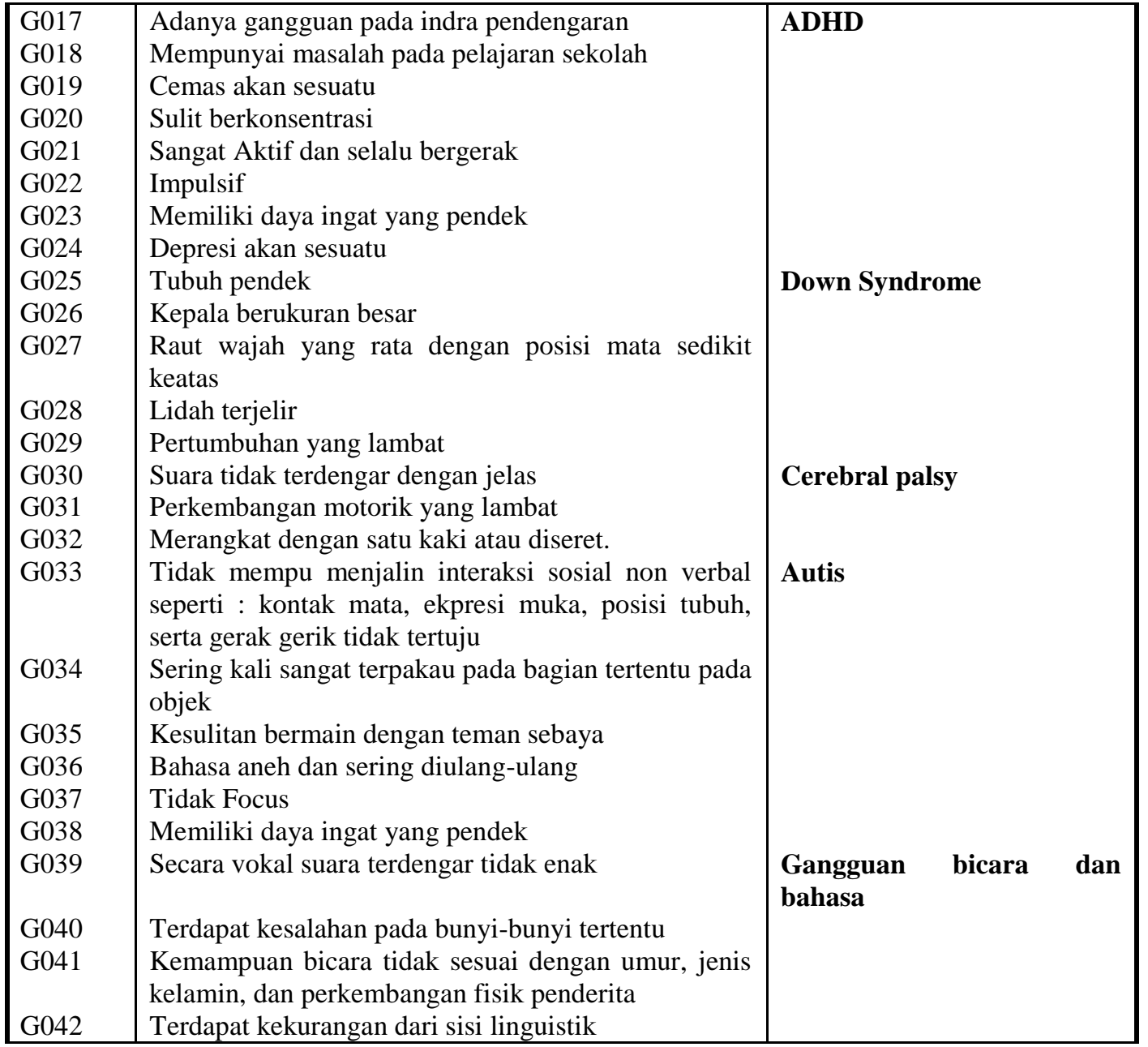

\subsection{Fakta Jenis Gangguan Perkembangan Pada Anak}

\begin{tabular}{|l|l|}
\hline P001 & Reterdasi Mental Sangat Berat \\
\hline P002 & Reterdasi Mental Berat \\
\hline P003 & Reterdasi Mental Moderat \\
\hline P004 & Reterdasi Mental Ringan \\
\hline P005 & Down Syndrome \\
\hline P006 & Cerebral Palsy \\
\hline P007 & Gangguan Autisme \\
\hline P008 & Gangguan Pemusatan Perhatian dan Hyperaktivitas (ADHD) \\
\hline P009 & Gangguan Bicara dan Bahasa \\
\hline
\end{tabular}

Berdasarkan fakta - fakta yang telah di kelompokkan pada tabel 4.5. dan 4.6 maka dapat di terapkan ke dalam aturan-aturan (Knowledge Base) yang di tampilkan pada tabel 4.7 berikut ini :

Tabel 4.7 Aturan (Rule)

IF Tingkat IQ kurang dari 19

And Sangat terbelakang

And Koordinasi otot sedikit sekali

And Kemungkinan tidak dapat berbicara atau berjalan

And tidak focus

Then Reterdasi mental berat, $\mathrm{CF}: 1$

IF Tingkat IQ antara 36 s.d 31

And Bisa berbicara atau belajar berkomunikasi

And Kesadaran sosial kurang 


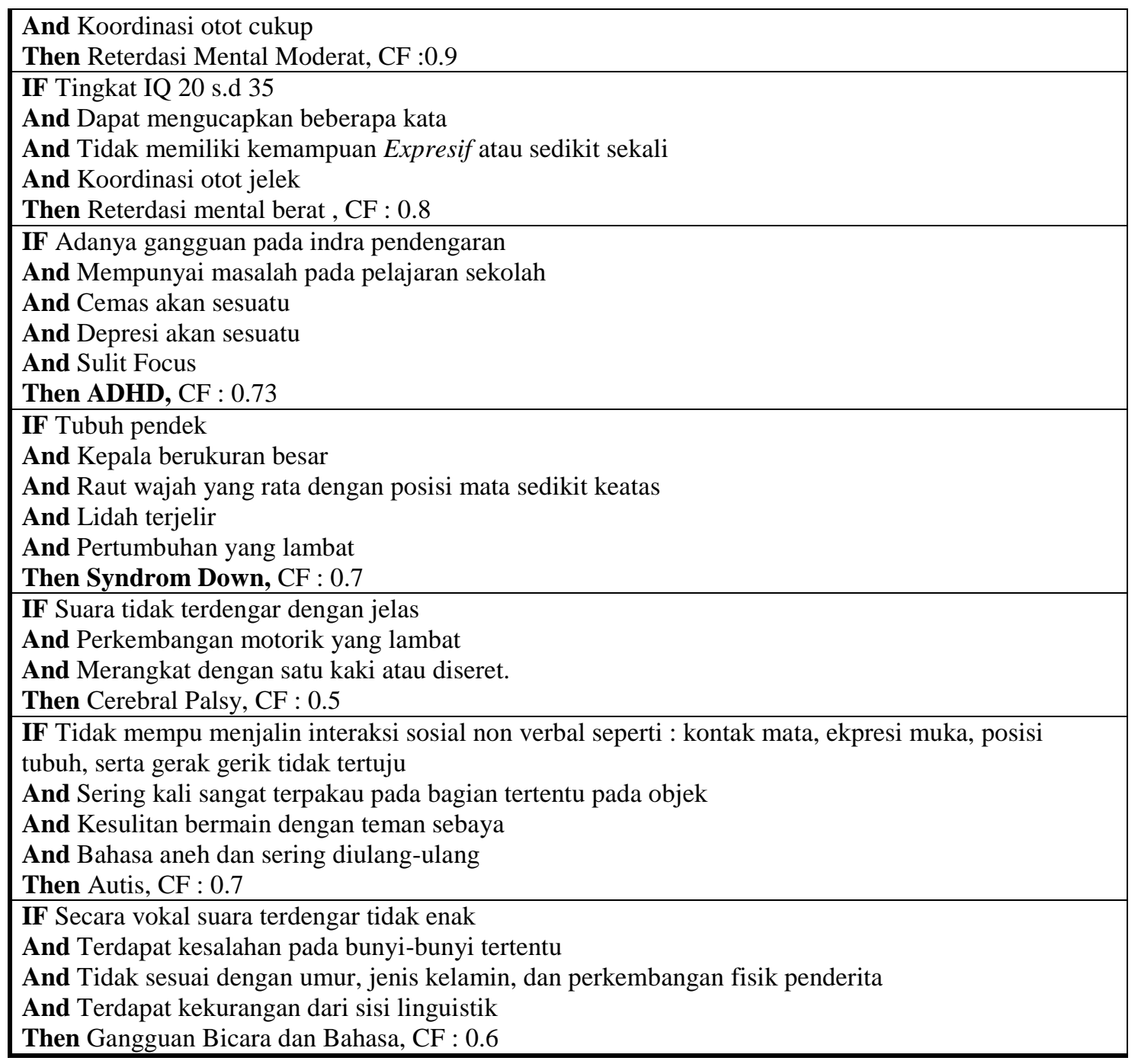

\subsection{Explaining Facilities ( Fasilitas Penjelasan )}

Fasilitas penjelasan sistem pakar dirancang dengan tujuan untuk memberikan penjelasan kepada penderita gangguan bagaimana sistem pakar ini bekerja.

\subsubsection{Analisis Interface}

Rancangan antar muka layanan (interface) Sistem Pakar Gangguan Perkembangan Pada Anak, terdiri dari 2 bagian, bagian ke pertama adalah user interface, pada bagian ini terdiri dari beberapa halaman :

1. Halaman Penjelasan SP ( Explaination Facilities )

2. Halaman input data pasien

3. Halaman diagnosa

4. Halaman Cetak Hasil diagnose

sedangkan bagian ke dua adalah admin interface yang terdiri dari :

1. Halaman input jenis gangguan / penyakit

2. Halaman input gejala

3. Halaman Input Aturan (rule)

Pada saat user login sebagai user atau pasien hanya dapat menginput data pasien, input gejala, serta besaran nilai kepastian (CF), user tidak bisa mengedit ataupun menghapus gejala ataupun jenis gangguan, hal ini dilakukan untuk lebih meningkatkan keamanan dari sistem pakar ini. Selain itu, user atau pasien yang akan mengdiagnosa ada tidaknya gangguan perkembangan pada anak, terlebih dahulu harus menginputkan data diri pasien dan menu diagnosa akan non aktif hal ini dimaksudkan agar pasien yang mengunakan sistem pakar ini lebih terdata.

Sedangkan user yang login sebagai admin, sistem akan memberikan tingkat otorisasi penuh untuk menginput gejala, jenis gangguan, serta mengedit dan menghapus gejala dan jenis gangguan yang ada. 
Jurnal Sakinah Dharmasraya, Vol. 2, No. 2, 2017

\subsection{Perancangan Sistem}

Berikut ini adalah rancangan halaman layanan utama, pada halaman ini terdapat bagian utama yaitu login area, dan halaman pembuka.

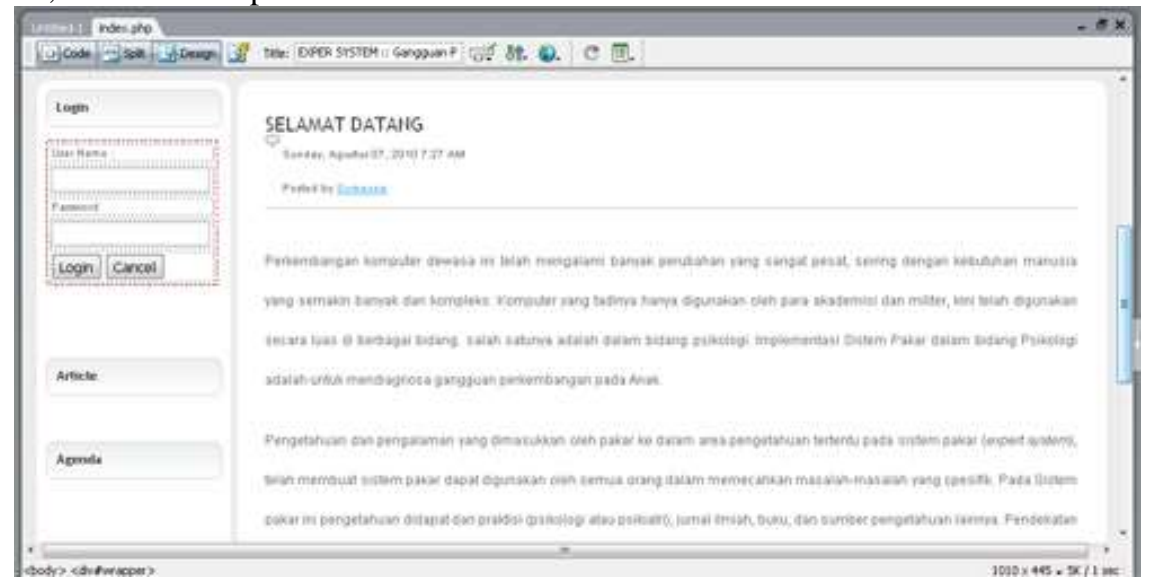

Gambar 4.3 Gambar Halaman Home

\subsubsection{Rancangan Halaman login.}

Pada halaman login, user diminta untuk menginputkan username dan password, dimana pada halaman login ini user akan dibedakan menjadi user atau pasien dan admin. Hak akses diberikan dengan tujuan untuk melindungi data dan informasi, user yang login sebagai pasien hanya bisa menginputkan data pasien, memasukkan gejala-gejala yang dialami, sedangkan untuk menginput jenis gangguan, gejala serta rule dari sistem pakar hanya diberikan kepada user yang login sebagai admin. Berikut ini adalah tampilan halaman login :

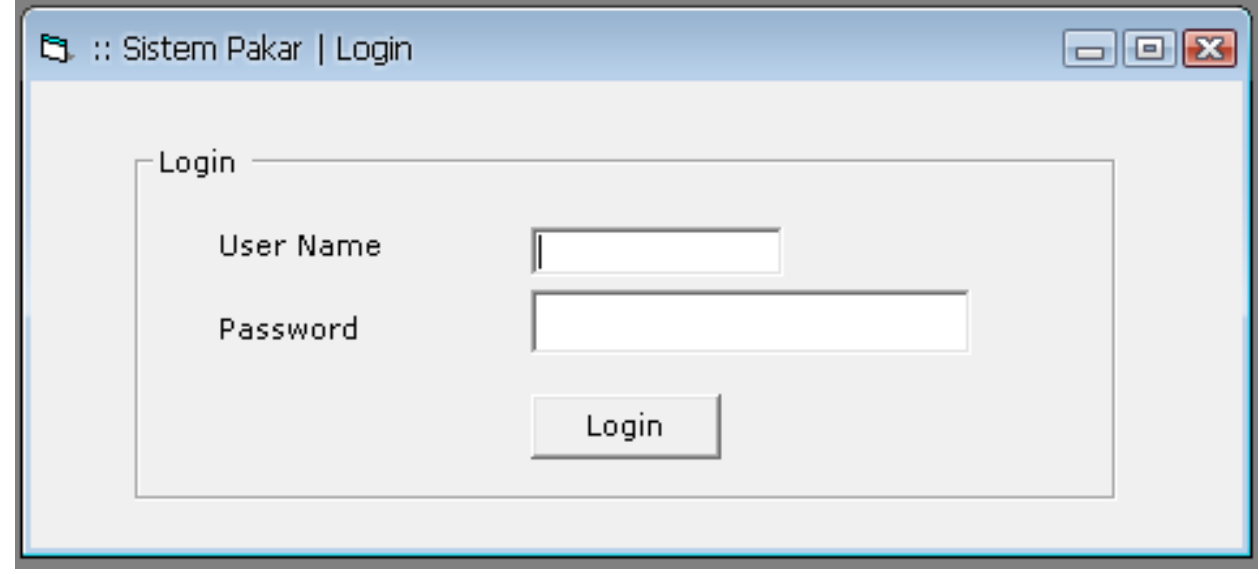

Gambar 4.4 Gambar Halaman Login

\subsubsection{Form Input Pasien (User)}

User yang mengunakan sistem pakar ini terlebih dahulu harus login sebagai user atau pasien, kemudian memilih menu input data pasien yang kemudian disimpan di database pada tabel user. Berikut adalah gambar halamana Input Data User / Pasien 
Jurnal Sakinah Dharmasraya, Vol. 2, No. 2, 2017

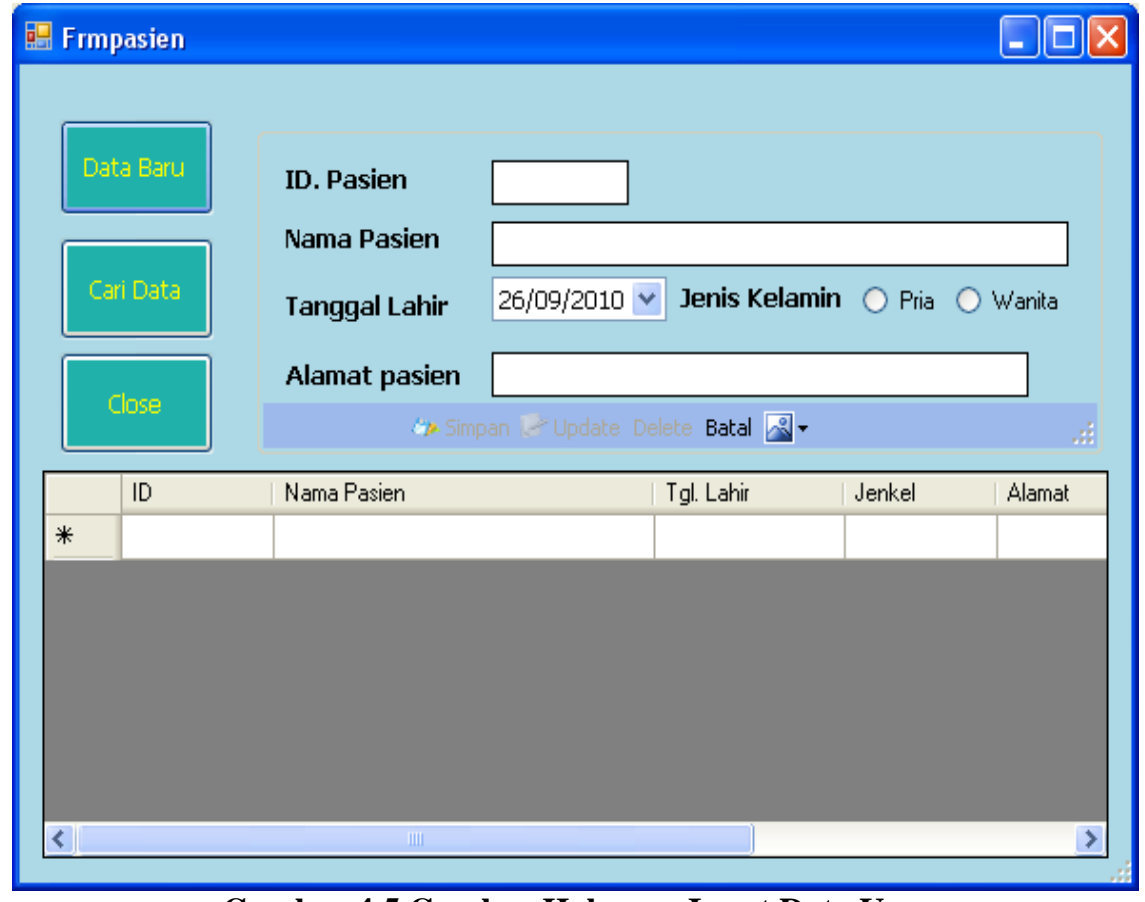

Gambar 4.5 Gambar Halaman Input Data User

\subsubsection{Rancangan Halaman Diagnosa / Entry Pertanyaan.}

Pada halaman diagnosa sistem pakar akan menampilkan pertanyaan-pertayaan yang berhubungan dengan gejala suatu gangguan perkembangan, selanjutnya user atau pasien akan menjawab pertanyaan tersebut dengan memilih ( check list ) pada pertanyaan yang didasarkan pada gejala yang dialami oleh pasien tersebut berserta nilai CF. Selanjutnya klik tombol Diagnosa untuk melihat diagnosa. Berikut ini adalah rancangan halaman diagnosa

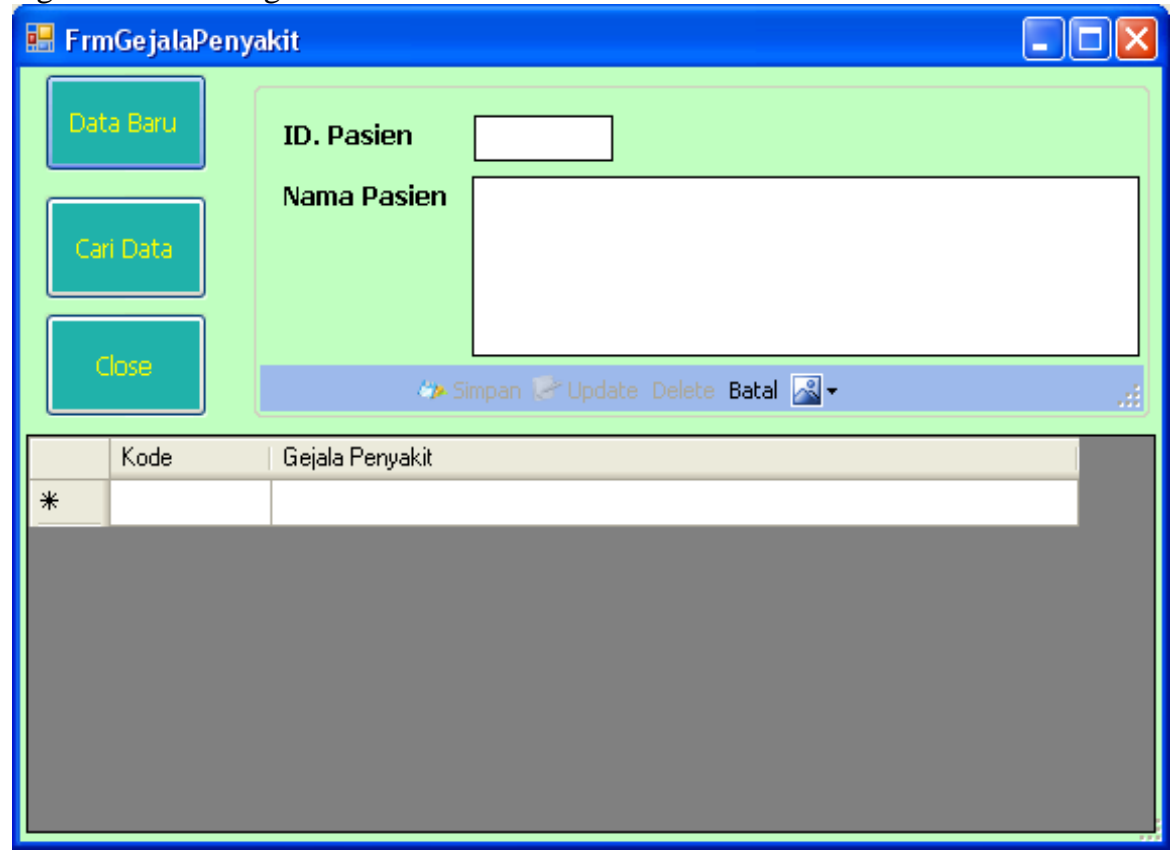

Gambar 4.6 Gambar Halaman Diagnosa

\subsubsection{Rancangan Laporan Hasil Diagnosa}

Setelah user melakukan diagnosa dengan mengisikan gejala yang dirasakan oleh pasien beserta besaran nilai cf maka sistem pakar akan menampilkan laporan hasil analisa berupa jawaban atas pertanyaan sistem, jenis gangguan, nilai $c f$ serta solusi dari jenis gangguan tersebut. 


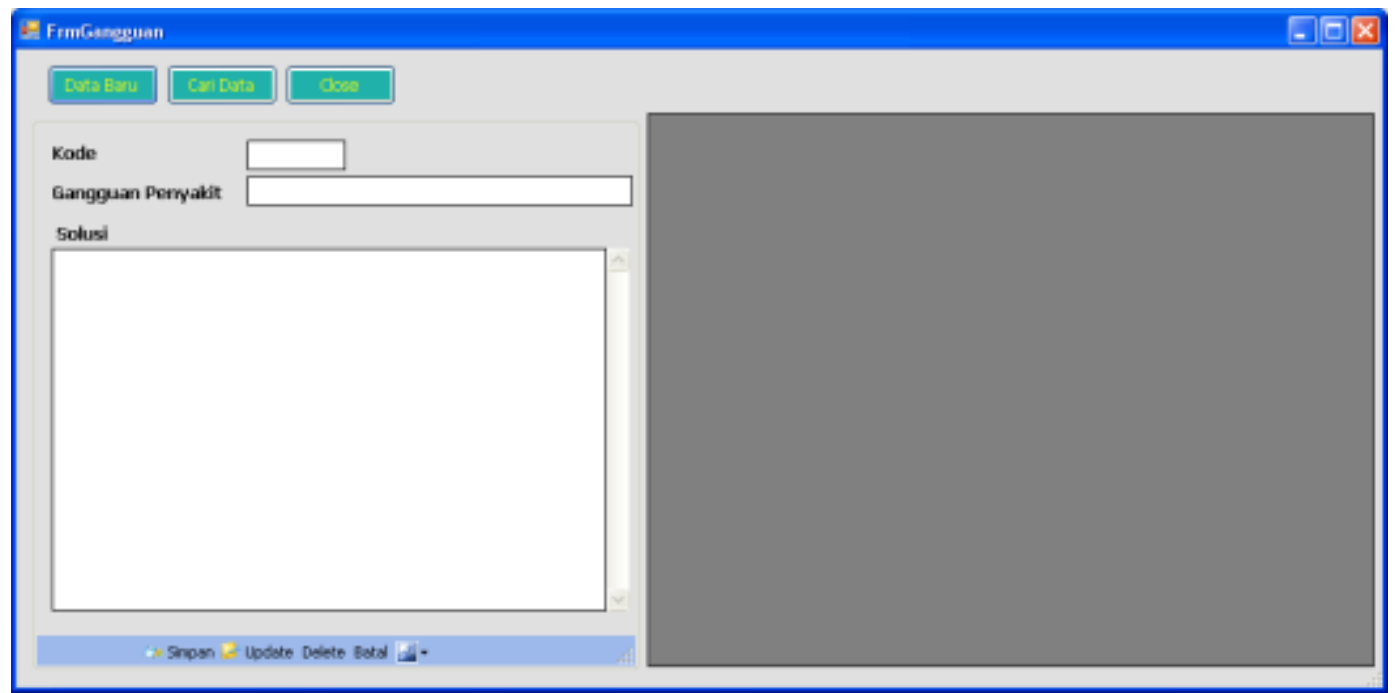

Gambar 4.7Gambar Form Hasil Diagnosa

\subsubsection{Rancangan Form Jenis gangguan / Penyakit}

Form Entry jenis gangguan akan ditampilkan jika user login sebagai admin, dimana admin akan memasukkan pengetahuan / knowledge mengenai jenis gangguan, nilai cf yang berasal dari pakar, serta solusi dari jenis gangguan tersebut. Berikut ini disain entry jenis gangguan

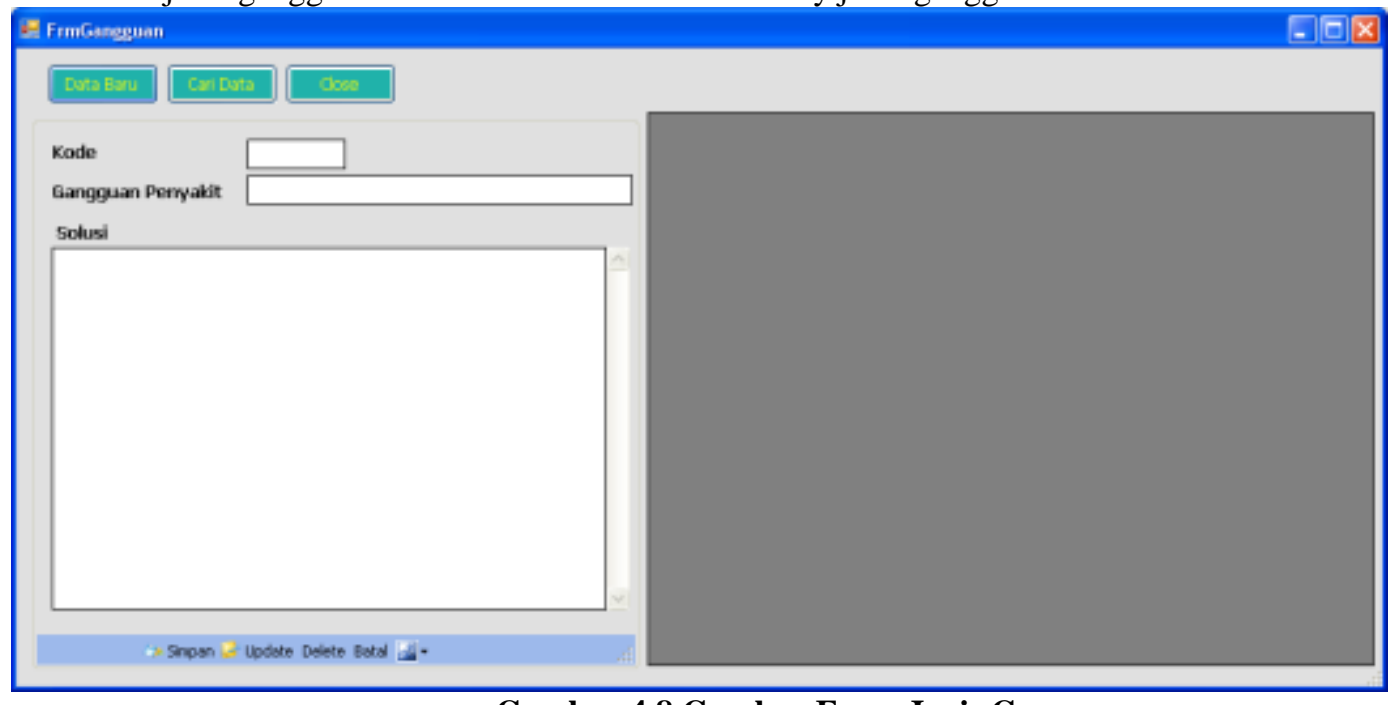

\subsubsection{Rancangan Form Gejala}

Data gejala diinputkan oleh pakar, pada form gejala ini berisi kode gejala, dan nama gejala. Namun demikian kedepannya sistem pakar ini dapat dikembangkan lagi sehingga bukan hanya admin yang menginput gejala tapi juga user, jika terdapat suatu gejala pada suatu jenis gangguan tetapi belum ada pada basis pengetahuan. 
Jurnal Sakinah Dharmasraya, Vol. 2, No. 2, 2017

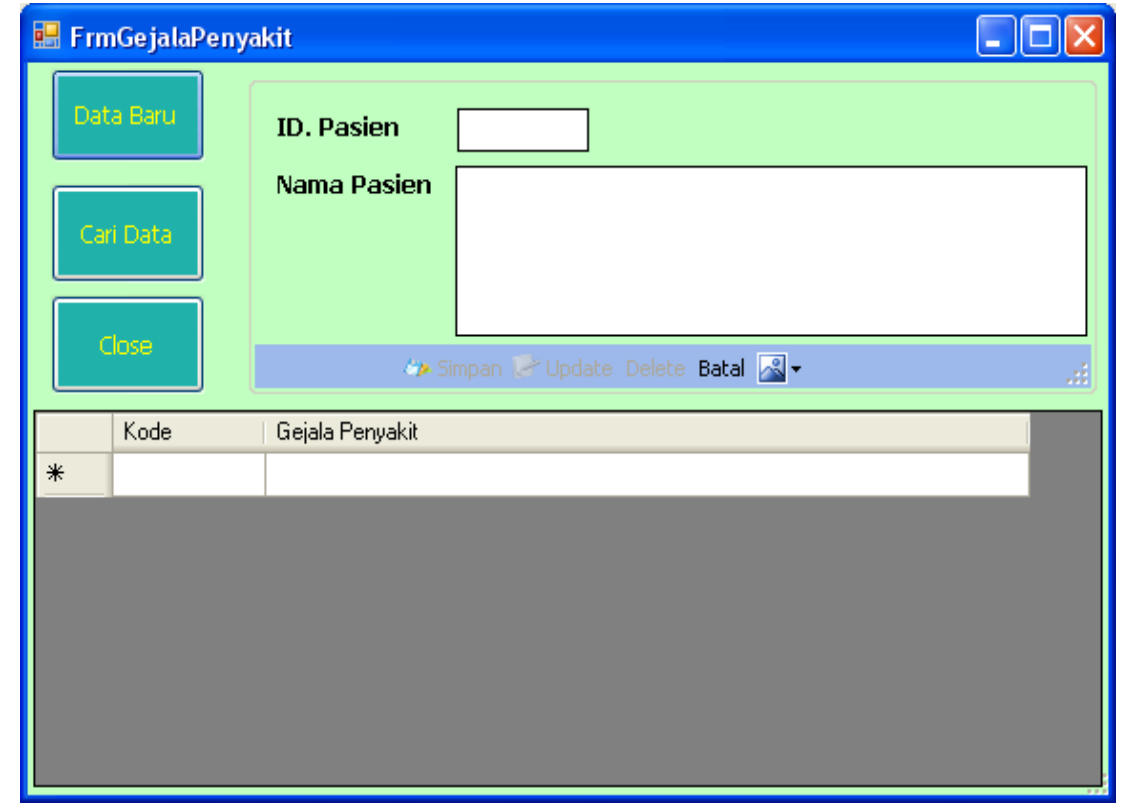

Gambar 4.9 Gambar Form Jenis Gangguan

\subsubsection{Rancangan Form Rule}

Form rule terdapat pada admin sites dimana hanya admin saja yang bisa melakukan pengaturan rule ini, pada form rule ini inference engine bekerja. Berikut ini disain form rule.

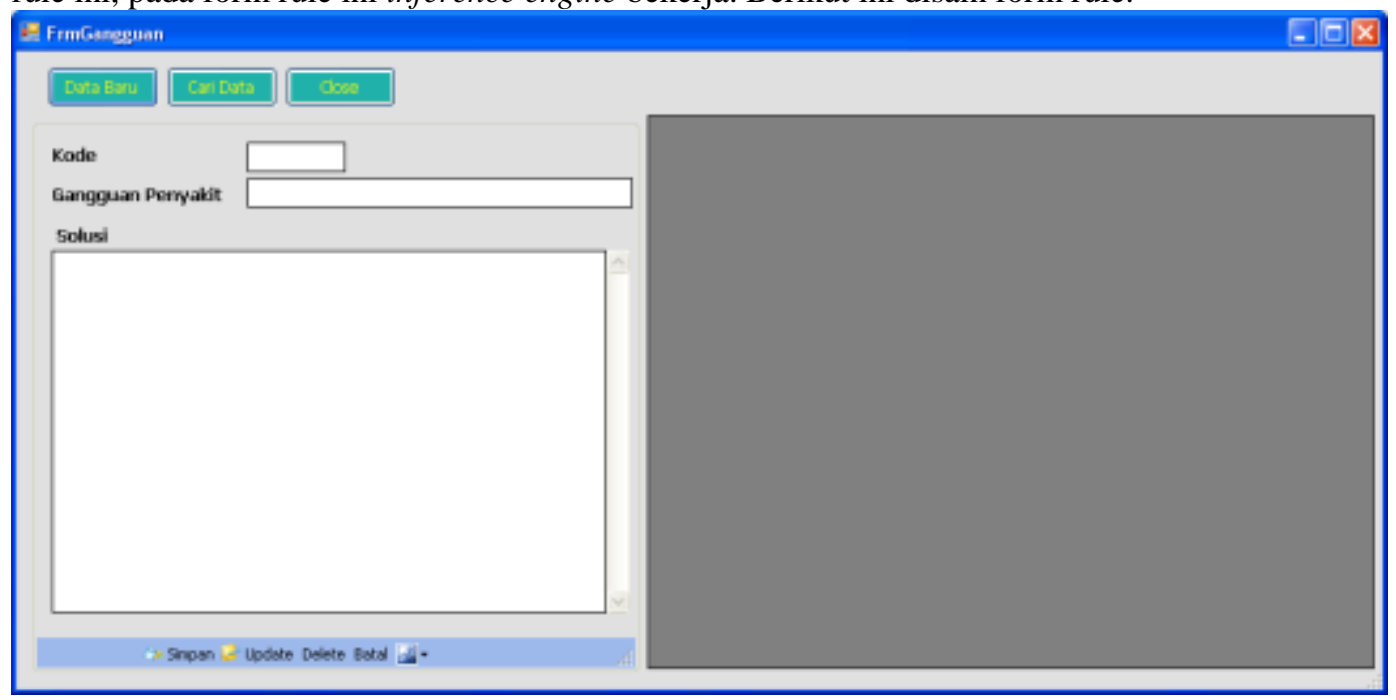

Gambar 4.10 Gambar Form Jenis Gangguan Data Kriteria

\section{Kesimpulan}

Berdasarkan penelitian dan pembahasan yang dilakukan, maka dapat disimpulkan beberapa hal sebagai berikut :

a) Ada 4 faktor yang menyebabkan terjadinya gangguan keterbelakangan mental pada anak. Faktor penyebab tersebut diperoleh dari jawaban atas pertanyaan yang diberikan sistem, sehingga akan dihasilkan diagnosa faktor apa yang menyebabkan terjadinya gangguan keterbelakangan mental tersebut.

b) Gangguan keterbelakangan mental ini juga bisa diklasifikasi tingkatannya berdasarkan kriteria dan gejala-gejala yang dialami pasien

c) Sistem pakar yang dirancang dapat mendiagnosa gangguan perkembangan pada anak (Keterbelakangan Mental) berdasarkan data tanya jawab yang dimasukkan.

d) Penalaran fordward chaining dengan metode Certainty Factor bisa digunakan untuk melakukan penelusuran faktor-faktor dan kriteria-kriteria untuk mendapatkan hasil diagnosa gangguan perkembangan anak.

e) Output (Keluaran) dari sistem ini dalam bentuk informasi apakah seorang anak mengalami gangguan keterbelakangan mental atau tidak dan juga informasi tingkatan dari Keterbelakangan mental (Retardasi.Mental) yang dialami anak tersebut. 
Jurnal Sakinah Dharmasraya, Vol. 2, No. 2, 2017 
Jurnal Sakinah Dharmasraya, Vol. 2, No. 2, 2017

\section{DAFTAR PUSTAKA}

[1] Halgin, richerd p \& Susan krauss wgitbourne, 2010. Perspekstif Klinis pada Gangguan Psikologis Jakarta : Selemba Humanika.

[2] Maslim, Rusdi, 2014. Bagian Ilmu Kedokteran Jiwa FK. Jakarta:PT Nuh Jaya - Jakarta.

[3] Dharwiyanti, 2015. Pemodelan Visual dengan UML. Yogyakarta: Graha Ilmu.

[4] Hartati, Sri, \& Iswanti, Sari.2018. Sistem Pakar dan Pengembangannya. Yogyakarta: Graha Ilmu.

[5] Martin, Oxam, 2015, Konsep Dasar Sistem Pakar. Yogyakarta: Andi Offset.

[6] Nugroho, Adi, 2017, Rekayasa Perangkat Lunak Menggunakan UML dan Java.Yogyakarta : ANDI.

[7] Nugroho, Bunafit, 2008, Membuat Aplikasi Sistem Pakar Dengan PHP dan Editor Dreamwaver. Yogyakarta : Gava Media.

[8] Kusumadewi, Sri, 2013, Artificial Intelligenci (Teknik dan Aplikasinya). Yogyakarta: Graha Ilmu.

[9] Turban, Efraim, 1995. Decision Support Systems and Intelligent System. United States of America: Pretince - Hall International, Inc.

[10] Andikos, AF, \& Ali, Gunawan (2016). Expert system for decision support division of inheritance according to islamic law. Vol. 3, No. 5. IAES International Journal Artificial Inteligence (IJ-AI). ISSN: $2252-8938$ 